\title{
CORRECTIONS
}

\section{Publisher Correction: The machineries, regulation and cellular functions of mitochondrial calcium}

Carlotta Giorgi, Saverio Marchi and Paolo Pinton (1)

Nature Reviews Molecular Cell Biology (2018) https://doi.org/10.1038/s41580-018-0052-8

Published online 24 August 2018

In the original version of the article, sentences highlighting references 108, 137 and 175 incorrectly refer to other items in the reference list: reference 106, 132 and 169, respectively, which were corrected - in order - to reference 110,136 and 176. The changes have been made in the HTML and PDF versions of the manuscript.

https://doi.org/10.1038/s41580-018-0066-2 I Published online 24 September 2018 